\title{
British and Australian Corporate Communication: A Socio-Linguistic Perspective
}

\author{
Elena N. Malyuga ${ }^{1}$, Maria Ivanova ${ }^{2} \&$ Rita Feigina $^{1}$ \\ ${ }^{1}$ Peoples' Friendship University of Russia (RUDN University), Moscow, Russia \\ ${ }^{2}$ Maxim Gorki Institute of Literature and Creative Writing, Moscow, Russia \\ Correspondence: Peoples' Friendship University of Russia (RUDN University), Moscow, 6 Miklukho-Maklay \\ Str., Russia. E-mail: en_malyuga@hotmail.com
}

Received: June 9, 2020 Accepted: July 8, 2020 Online Published: July 14, 2020

doi:10.5539/ijel.v10n5p125 URL: https://doi.org/10.5539/ijel.v10n5p125

\begin{abstract}
In this study, the corpora of British and Australian corporate communications were compared with the aim of specifying their sociolinguistic features in the context of five lexical and stylistic markers: professional jargon, as well as expressive, colloquial, uncodified and evaluative lexis. Lexical and stylistic characteristics of corporate communication from the point of view of a sociolinguistic approach were analyzed using transcripts of British and Australian communicative corporate interactions. The methods of continuous sampling, comparative, lexical-stylistic and sociolinguistic analysis were implemented to process an assembled corpus of 158 authentic transcripts. Based on the results of the analysis, quantitative data were compared, reflecting the volume of use of the indicated lexical-stylistic markers in the two samples. Quantitative data were subsequently analyzed to determine sociolinguistic characteristics that can be assessed as specific features of the communicative behavior of British and Australian superiors in dealing with subordinates. For each of the markers of lexical-stylistic differentiation under consideration, the two samples analyzed in the work showed differing results of a varied and at the same time exponential degree of discrepancy.
\end{abstract}

Keywords: sociolinguistics, corporate communication, British English, Australian English, lexical-stylistic means

\section{Introduction}

Effective modern communication is aimed at establishing strong business contacts, facilitating the negotiation process, and helping to identify significant interaction patterns. Proper targeted use of corporate communication is the key to a stable business relationship and successful deals. The rapidly evolving corporate environment has given impetus to the emergence of numerous language-related research having to do with the many processes taking place in the corporate world.

The purpose of this study is to determine the lexical and stylistic characteristics of corporate communication produced by the representatives of British and Australian corporate communities using a sociolinguistic approach that allows to study the issues associated with the social nature of the language, its social functions, the role that language plays within a society, and the mechanisms governing the interrelation between social and linguistic factors. This approach can help identify significant differences that are characteristic of the British and Australian speech communities of interest to this paper.

In the study, speech communities are referred to as groups of people sharing a set of linguistic norms and expectations regarding the use of language (Jacquemet, 2019). A speech community implies certain norms of language use through life relying on reciprocal communicative engagement (Salmon et al., 2019), and primarily refers to speaker-listener interaction patterns established between communication partners, when the application of language knowledge occurs as a matter of everyday communicative practices within the community (Xu, 2016).

At the same time, a speech community is actualized not just through any notable agreements in the use of language units: style can differ both in terms of formal linguistic and widely ranging stylistic prerequisites (Yu, 2016), therefore the very term "speech community" and the communicative behavior of speech community members are often investigated alongside notions associated with cultural, dialectal, institutional, hierarchical, 
gender-related and other concepts.

\section{Theoretical Framework}

Sociolinguistics is a crucial reference point for communication theory. The subject area of Sociolinguistics includes an extensive range of problems related to the active role that language plays within a society; the national literary language is being established as a nation grows and becomes an important factor in its further consolidation (Meyerhoff, 2018). The task of Sociolinguistics lies not only in studying the reflections in the language of various social phenomena and processes, but also in investigating the role of the language among the social factors that determine the social functioning and evolution (Williams, 2018). Sociolinguistics studies the whole complex of problems reflecting the bilateral nature of the relationship between language and society. The key methods used to collect sociolinguistic data are questionnaires, interviews, a sociolinguistic experiment, anonymous observation of conversational practices in public places, observation of spontaneous colloquial speech (including as recorded in a textual representation) with the subsequent interpretation of its content (Coupland, 2016).

Speaking about the linguistic aspects of communication theory, scientists distinguish a phenomenon referred to as "creolized text", which is the interconnection of linguistic and non-linguistic means, which also contain the verbal part associated with the language, and the non-verbal part associated with the system of signs (Kouwenberg \& Singler, 2018). Nevertheless, regardless of which of the two aspects is being analyzed, an important component is the need to use proper rules of speech etiquette, which, in the case of focus on verbal interaction, include special speech formulas characteristic of a particular speech community (Malyuga, 2019).

Communication is a process that is characterized by a mutual exchange of information based on various social, cultural, political, cognitive, and discursive factors (Fuoli \& Hart, 2018). Corporate communication considered in this study can be effective only if it helps to achieve certain corporate goals and maintain a corporate image. At the same time, the cultural etiquette of corporate communication covers such factors as the context of interaction (meetings, negotiations, etc.), body language, corporate culture, etc. (Malyuga et al., 2019).

Corporate communication is a popular research subject among many linguists. It is aimed at achieving certain goals, and can be described as a process of exchanging corporate messages with business partners in order to maintain two-way communication (Lerbringer, 2018). There are certain characteristics of corporate communication that are of great importance for corporations, companies, and brands maintaining their image: promotion of a company profile; minimization of discrepancies between corporate identity and company features; delegation of tasks through communication; formulation and implementation of effective procedures for the purposes of decision making; mobilization of internal and external support; international coordination (Kaul \& Choudhri, 2017).

The effectiveness of corporate communication, and, therefore, social interaction, is determined both by the features of this activity itself, which takes place in certain specific conditions in the context of various situations, and by the socio-psychological background of communication partners (Palmieri \& Mazzali-Lurati, 2017). Of no lesser importance is the level of communicative competence (Mart, 2018) that allows an individual or company to achieve communicative goals. Corporate communication is critical to brand image and organizational value, as well as maintaining corporate identity (Silberer, 2005).

\section{Method}

Lexical and stylistic characteristics of corporate communication from the point of view of a sociolinguistic approach were analyzed using transcripts of British and Australian communicative corporate interactions (Romaine, 2001; Schegloff, 2000). The methods of continuous sampling, comparative, lexical-stylistic and sociolinguistic analysis were implemented to process an assembled corpus of 158 authentic transcripts.

Research descriptive and interpretive validity is achieved by the primary principles for data collection which are based on the quantitative and qualitative analysis of the authentic transcripts realised by their careful examination.

Therefore, the method of continuous sampling is applied with the aim to find out the frequency of occurrence of lexical-stylistic means in the authentic British and Australian transcripts.

Comparative method is selected in order to distinguish the phenomena between two speech communities, to describe it from the sociolinguistic perspective bearing in mind links that create interconnection between social roles, corporate aims, gender aspects, age, and background of executives occupying top rated positions.

Lexical-stylistic analysis is used in this research to pinpoint the extensive variety of lexical-stylistic peculiarities 
in British and Australian corporate interactions.

The study registered 173 stylistically marked lexical units that reflect the specifics of top-down communication in the texts of the British sample, and 175 stylistically marked lexical units reflecting the specifics of top-down communication in the texts of the Australian sample

Sociolinguistic analysis helps to delineate the situational context of British and Australian communicative corporate interactions that expands in-depth scientific understanding of this approach applied to corporate communication.

The transcripts chosen for the research have been compared with the purpose of exposing any recurrent or infrequent lexical-stylistic means. Therefore, the process of analysis involved several steps: (1) to compile a corpus of authentic transcripts based on selection criteria (companies of different market segments); (2) careful examination of authentic transcripts on recurrent lexical-stylistic phenomena to be found in the text; (3) application of lexical-stylistic analysis; (4) assumption concerning the most frequently used lexical-stylistic means that makes it able to distinguish sociolinguistic aspects.

The concept of this article is to prove that 'British and Australian corporate communication samples are abundant with professional lexis; among them are professional jargon, expressive, colloquial, uncodified, and evaluative lexis, respectively. The recurrent phenomenon is considered professional jargon (81 British samples and 59 Australian) that indicates the influence of specific communicative features in speech behaviour of business partners, highlights the subordination aspect, alludes hierarchical relationships between superior management and subordinates, as well as affiliates to single professional and linguistic identity'.

The nature of the communication is influenced by many factors including size and sector of a company, the number of employees. Thus, this research focuses on companies that are located in different market segments such as oil and gas, asset management, etc. that explains specific lexis used in terms of different target audience.

In the framework of constant internationalization and business activities, the knowledge and understanding of the basics is the key to successful transactions, negotiations and deals. Understanding the specifics of corporate communication also influences the inflow of foreign clients and business partners (Malyuga, 2019).

Big conglomerates, financial credit organizations, banks, and stock exchanges are considered types of companies that are of particular interest in this research. Such companies usually have a number of employees in the range of 30,000-40,000 and it makes corporate communication as an important and valuable tool in achievement of corporate goals.

\section{Results and Discussion}

The sociolinguistic analysis of the material was put in place not as a means of penetrating into the linguistic behavior of certain groups of the British and Australian communities, but as a means of establishing the norms of the English language of interest to us. The interplay of language and society is an indisputable fact. However, this relationship can be traced at different levels of the linguistic structure with varying degrees of clarity.

Perhaps it would be appropriate to say that the lexical composition of a particular language is the one that is most responsive to changes taking place within a society (Grünhage-Monetti \& Braddell, 2019).

In terms of the sociolinguistic oppositions presented in the analysis, the article explores the factor of speaker and addressee status in the corporate hierarchy. If educational background and professional status are almost directly related to the social status of a person, then gender and age are related to natural differentiation. However, in any society there is a socialization of natural differentiation and the natural behavioral patterns of a person acquire social significance (Vouillemin, 2020).

The article analyzes how the phenomenon of corporate communication varies depending on the speaker's place in the corporate hierarchy. The lexical-stylistic analysis revealed the characteristics that helped formulate some sociolinguistic characteristics of British and Australian corporate communication.

We have analyzed transcripts of corporate interaction produced by representatives of the British and Australian corporate communities. In this case, a top-down type of vertical communication was considered, directed from top to bottom-from managers to the subordinates. The study registered 173 stylistically marked lexical units that reflect the specifics of top-down communication in the texts of the British sample, and 175 stylistically marked lexical units reflecting the specifics of top-down communication in the texts of the Australian sample.

The target audience of speakers included executives with professional degrees in marketing, finance, business, and the like. These are experienced specialists with valuable experience in their field and with high professional status and educational background. Their speech is distinguished by a variety of lexical and stylistic 
characteristics that are directly related to their role in the corporate community, status, position, age and professional experience (Feigina, 2020).

The target audience of recipients included company employees of varying status, directly involved in the company's activities and corporate interaction processes, which implies interaction with senior management.

For the purposes of this study, the following markers of lexical-stylistic differentiation were of outmost interest, which is why these became the focus of the analysis:

1) professional jargon (a type of jargon used by a group of people united through professional affiliation);

2) expressive lexis (emphatic vocabulary with a clear subjective connotation that allows the speaker to express their emotions to a certain degree);

3) colloquial lexis (vocabulary characteristic of situations of informal communication and therefore non-formalistic and spontaneous in nature);

4) uncodified lexis (substandard vocabulary not fixed in special dictionaries as a common norm);

5) evaluative lexis indicating positive or negative phenomena, as well as the speaker's attitude towards the subject of the statement (positive vs negative connotation).

The stylistically marked lexis used in both British and Australian corporate communications is multifunctional, and all of its functions are of great importance in speech. Thus, stylistically marked lexis endows the speech with a substandard or exalted tinge, affects the opinion of the subordinate, marks the communicative situation, gives the conversation a concise and accurate presentation, conveys assessments and emotions, characterizes the participants of communication through their speech, reflects the style of speech and may increase the expressiveness of communicative interaction in general. In this study, each of the above five markers was subsequently analyzed from the point of view of the corresponding sociolinguistic implications, namely:

1) the volume of professional jargon used - as an indicator of the distinctive unity of the superior and subordinates as representatives of a shared professional and linguistic identity;

2) the volume of expressive lexis used - as an indicator of the orientation of communication towards conviction with a possible status indication;

3) the volume of colloquial lexis used - as an indicator of the level of trust between the superior and subordinates;

4) the volume of uncodified lexis used - as an indicator of the social distance between the superior and subordinates;

5) the volume of evaluative lexis with positive connotation used - as an indicator of the degree of positive assessment by the superior reflecting subordinates' professional qualities.

According to the results of the study, in conformity with the specified analysis parameters, in communication with subordinates, representatives of the senior management of British and Australian companies use stylistically marked lexis in corporate communication in the following proportions (Figure 1):

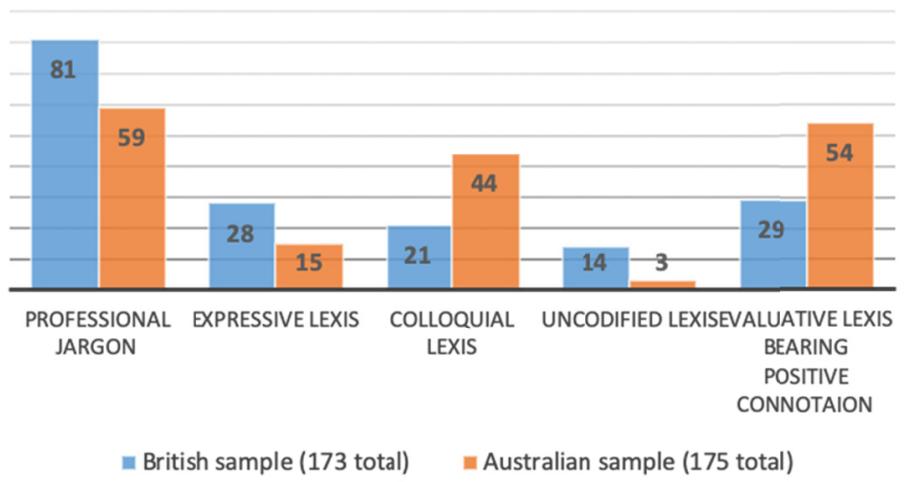

Figure 1. Volume of stylistically marked lexis registered in the British and Australian samples 
As can be seen from the histogram, for each of the markers of lexical-stylistic differentiation under consideration, the two samples analyzed in the work showed differing results of a varied and at the same time exponential degree of discrepancy.

In terms of the volume of professional jargon used, the British sample showed a significant breakaway from the Australian one ( 81 vs 59 tokens, respectively), which indicated that at the language level British corporate communication showed a more clearly traceable unity of superior management and subordinates as representatives of a single professional and linguistic identity. Professional jargon in the studied samples was used by speakers in accordance with various contextual premises: in naming companies existing in the corporate world (for example, British Petroleum, Aviva PLC, Westfarmers); in naming job titles existing in the corporate world (for example, down manager, sales manager, chief accountant, production supervisor, training manager, $\mathrm{CEO}, \mathrm{CFO}, \mathrm{COO}, \mathrm{CTO}, \mathrm{VP}$ ); in naming certain procedures effectuated in the corporate world (for example, negotiating, bargaining, lending, planning, meeting minutes); in naming relevant financial transactions (for example, financial monitoring, asset managing, investing, trading, capital raising).

In terms of the volume of expressive lexis used in the British sample, a quantitative margin was also recorded in comparison with the Australian sample, 28 vs 15 tokens, respectively, which can be considered as an indicator of the greater focus of British corporate communication on convincing subordinates, with the possible superior status indication.

In terms of the volume of colloquial lexis used, the Australian sample comes out on top in quantitative terms, 44 tokens compared to 21 tokens in the British sample. Such data act as an indicator of a higher level of trust, traditionally established between the superior and subordinates as participants in Australian corporate communication.

In terms of the volume of uncodified lexis used, a significant quantitative advantage was on the side of the British sample, 14 tokens in comparison with 3 tokens in the Australian sample. Such indicators suggest the presence of a greater social distance between the superior and subordinates in the UK.

Finally, in terms of the volume of evaluative lexis bearing positive connotation used, the quantitative data of the Australian sample appear higher than the resulting data obtained in the analysis of the British sample, 54 vs 29 tokens, respectively, which in the context of this study of sociolinguistic features of corporate communication indicates a more pronounced trend towards positive assessment of the professional qualities of subordinates on the part of Australian superiors.

\section{Conclusion}

Language is social not only in its purpose, but also in its use: the social factor can represent a certain idea, concept and affect both the language as a whole and the nature of corporate communication. The peculiarity of corporate communication as a social phenomenon is that corporate communication is a process of interaction of linguistic personalities with the aim of transmitting, receiving, or exchanging information needed to implement joint professional, business and corporate activities. In a broad sense, corporate communication is understood as the process of exchanging corporate messages with external business partners and internal colleagues in order to maintain two-way communication. At the same time, the features of speech production that are inherent to the studied participants in corporate communication related to their roles in the corporate community, status, age, professional qualifications and other socially and professionally significant factors.

In this study, the corpora of British and Australian corporate communications were compared with the aim of specifying their sociolinguistic features in the context of five lexical and stylistic markers: professional jargon, as well as expressive, colloquial, uncodified, and evaluative lexis. Based on the results of the analysis, quantitative data were compared, reflecting the volume of use of the indicated lexical-stylistic markers in the two samples. Quantitative data were subsequently analyzed to determine sociolinguistic characteristics that can be assessed as specific features of the communicative behavior of British and Australian superiors in dealing with subordinates.

\section{Acknowledgments}

This paper was financially supported by the Ministry of Education and Science of the Russian Federation on the program to improve the competitiveness of Peoples' Friendship University of Russia (RUDN University) among the world's leading research and education centers in 2016-2020.

\section{References}

Coupland, N. (Ed.). (2016). Sociolinguistics: Theoretical debates. Cambridge: Cambridge University Press. https://doi.org/10.1017/CBO9781107449787 
Feigina, R. (2020). Lexical peculiarities of professional jargon in corporate communication. Issues of Applied Linguistics, 37, 107-121. https://doi.org/10.25076/vpl.37.05

Fuoli, M., \& Hart, C. (2018). Trust-building strategies in corporate discourse: An experimental study. Discourse \& Society, 29(5), 514-552. https://doi.org/10.1177/0957926518770264

Grünhage-Monetti, M., \& Braddell, A. (2019). Language for work matters. Training, Language and Culture, 3(4), 27-35. https://doi.org/10.29366/2019tlc.3.4.3

Jacquemet, M. (2019). Beyond the speech community: On belonging to a multilingual, diasporic, and digital social network. Language \& Communication, 68, 46-56. https://doi.org/10.1016/j.langcom.2018.10.010

Kaul, A., \& Choudhri, V. (2017). Corporate communication through social media: Strategies for managing reputation. New Delhi: Sage.

Kouwenberg, S., \& Singler, J. V. (2018). Creolization in context: Historical and typological perspectives. Annual Review of Linguistics, 4, 213-232. https://doi.org/10.1146/annurev-linguistics-011415-040544

Lerbinger, O. (2018). Corporate communication: An international and management perspective. New York: John Wiley \& Sons.

Malyuga, E. N. (2019). Emergent trends in English scientific discourse: Issues of research relevance and linguistic identity. Tomsk State University Journal of Philology, 58, 52-70. https://doi.org/10.17223/19986645/58/4

Malyuga, E., Maksimova, D., \& Ivanova, M. (2019). Cognitive and discoursive features of speech etiquette in corporate communication. International Journal of English Linguistics, 9(3), 310-318. https://doi.org/10.5539/ijel.v9n3p310

Mart, C. (2018). From communicative competence to language development. International Journal of English Linguistics, 8(2), 163-167. https://doi.org/10.5539/ijel.v8n2p163

Meyerhoff, M. (2018). Introducing sociolinguistics. New York: Routledge. https://doi.org/10.4324/9780429507922

Palmieri, R., \& Mazzali-Lurati, S. (2017). Practical reasoning in corporate communication with multiple audiences. Journal of Argumentation in Context, 6(2), 167-192. https://doi.org/10.1075/jaic.6.2.03pal

Romaine, S. (2001). Language in Society: An Introduction to Sociolinguistics (2nd ed.). Oxford: Oxford University Press.

Salmon, C. T., Poorisat, T., \& Kim, S. H. (2019). Third-person effect in the context of public relations and $\begin{array}{lllll}\text { corporate communication. Public Relations } & 101823 .\end{array}$ https://doi.org/10.1016/j.pubrev.2019.101823

Schegloff, E. A. (2000). Overlapping Talk and the Organization of Turn-taking for Conversation. Language in Society, 29, 1-63. https://doi.org/10.1017/S0047404500001019

Silberer, G. (2005). Corporate Communication with a Corporate Foundation: Another Option for Reputation Management. Georg August University, Gottingen, Germany.

Vouillemin, D. (2020). Business cultural training in a globalised economy. Training, Language and Culture, 4(1), 33-43. https://doi.org/10.22363/2521-442X-2020-4-1-33-43

Williams, G. (2018). Sociolinguistics: A sociological critique. London: Routledge. https://doi.org/10.4324/9780429434679

$\mathrm{Xu}, \mathrm{D}$. (2016). Speech community theory and the language/dialect debate. Journal of Asian Pacific Communication, 26(1), 8-31. https://doi.org/10.1075/japc.26.1.01xu

Yu, W. (2016). A study of catchwords from the perspective of speech community. Theory and Practice in Language Studies, 6(4), 804-809. https://doi.org/10.17507/tpls.0604.18

\section{Copyrights}

Copyright for this article is retained by the author, with first publication rights granted to the journal.

This is an open-access article distributed under the terms and conditions of the Creative Commons Attribution license (http://creativecommons.org/licenses/by/4.0/). 